УДК 82

\title{
E.A. Маркова
}

\section{АНГЛОЯЗЫЧНАЯ ЭЛЕГИЧЕСКАЯ ТРАДИЦИЯ И ПОЭЗИЯ И. БРОДСКОГО}

В данной статье рассматривается поэтическое творчество И.А. Бродского в контексте особой элегической традиции, связанной с ключевыми для англоязычной поэзии середины - конца ХХ века фигурами У.Б. Йейтса, Т.С. Элиота, У.Х. Одена и Ш. Хини. Цель данной статьи - проанализировать преемственность поэзии ХХ в., написанной на английском языке, на примере цепочки стихотворений-посвящений (элегий), в которой каждое последующее звено формально и образно отсылает к предыдущему. Сопоставление стихотворений указанных авторов позволяет не только продемонстрировать характерные особенности современной англоязычной элегии (в частности, неизбежную сопряженность этого жанра с темой назначения поэта и поэзии, которая у каждого автора раскрывается по-своему), но и рассмотреть влияние частных контактов, возникших между поэтами, на их творчество. Особое внимание уделяется поэзии Бродского как явлению, казалось бы, инородному англоамериканской и ирландской литературе и культуре. Анализ личной и творческой биографии Бродского, его конкретных стихотворений-посвящений, а также его эссеистики позволяет найти нити, соединяющие русского поэта с литературной традицией Великобритании, США и Ирландии.

Ключевые слова: взаимосвязи литератур; элегия; стихотворение-посвящение; И. Бродский; Ш. Хини.

DOI: $10.35634 / 2412-9534-2019-29-6-1030-1036$

Проблема и цель. Интерес Иосифа Александровича Бродского (1940-1996) к англоязычной литературе зародился еще в начале 1960-х гг., задолго до отъезда за границу. Одно из наиболее значимых увлечений молодого поэта - чтение произведений английских поэтов-метафизиков XVII в., в особенности Джона Донна. Именно с этим увлечением Виктор Куллэ связывает такие составляющие поэзии Бродского, как «изощренность метафорического мышления, склонность к парадоксу, эксперименты с ритмом и строфикой, смешение языковых пластов, ядовитый юмор, умение в композиции стихотворения, при самом извилистом его развитии, свести все ходы воедино» [10. С. 289].

Во время ссылки Бродский не только много пишет, но и читает, в том числе англоязычных авторов, прежде всего Т.С. Элиота и У.Х. Одена. Поэзия Элиота, развивавшаяся под влиянием метафизической школы и идей неоклассицизма, была близка Бродскому. Незадолго до отъезда из России он пишет стихотворение «Сретенье» на смерть А. Ахматовой, которое, как отмечают исследователи, является «продолжением стихотворения Т.С. Элиота “А Song for Simeon"» [10. С. 294]. Что же касается Одена, он сыграл важнейшую роль в жизни русского поэта, оказав ему всестороннюю помощь и поддержку, когда в 1972 г. Бродский оказался за границей.

В эссе «Как читать книгу» (1988) Бродский перечисляет тех англоязычных поэтов, творчество которых, с его точки зрения, заслуживает особого внимания: «Если ваш родной язык английский, я мог бы рекомендовать вам Роберта Фроста, Томаса Гарди, У.Б. Йейтса, Т.С. Элиота, У.Х. Одена, Марианну Мур и Элизабет Бишоп» [2. С. 84]. Таким образом, становится понятно, какие поэты оставили след в душе Бродского и, вероятно, в его творчестве. Мы остановимся на трех из них - Йейтсе, Элиоте и Одене - и добавим к ним еще одно важное имя - имя современника и друга Бродского, ирландского поэта Шеймаса Хини (Seamus Heaney, 1939-2013). Выбранная нами тема неоднократно привлекала внимание исследователей $[9 ; 11 ; 15 ; 17]$, и все они в большей степени фокусировались на Одене и Хини, чем на Бродском [9; 17], или на жанре элегии [15]. Мы же в рамках данной статьи рассмотрим, как англоязычная элегическая традиция, ассоциируемая с указанными именами, преломляется в творчестве Бродского и затем возвращается в русло английской поэзии.

28 января 1939 г. умирает ирландский поэт и драматург У. Б. Йейтс. Уистен Оден откликается на его смерть стихотворением «Памяти Йейтса» (In Memory of W. B. Yeats, 1939). По справедливому замечанию Г.М. Кружкова, элегия Одена была вдохновлена одним из последних стихотворений Йейтса «В тени Бен-Балбена» (Under Ben Bulben, 1938) [9, с. 351-352]. Сходство здесь не только в необычном для английской поэзии и потому узнаваемом размере, четырехстопном хорее, но в первую очередь в тематике. Стихотворение Йейтса датировано четвертым сентября 1938 г., то есть оно было написано всего за несколько месяцев до смерти поэта. В этом стихотворении Йейтс как бы подводит итоги своего долгого жизненного и творческого пути. Название стихотворения указывает на 
место, где поэт завещал себя похоронить (и был в итоге похоронен), - у подножия горы Бен-Балбен, которая находится в родном для Йейтса графстве Слайго, на северо-западе Ирландии, и в том или ином виде появляется во многих произведениях поэта (см., напр., стихотворения «Башня» (The Tower, 1927), «О политическом заключенном» (On a Political Prisoner, 1920), «Перед рассветом» (Towards Break of Day, 1920), пьесу «Диармайд и Грайне» (Diarmuid and Grania, 1901) и сборник «Кельтские сумерки» (The Celtic Twilight, 1893).

Само стихотворение, местами «темное» в духе позднего Йейтса, соткано из многочисленных отсылок к его более ранним произведениям и в первую очередь к тем из них, в которых нашли отражение идеи поэта о Мировой душе, Великом Колесе и перевоплощении души после смерти (речь идет прежде всего о «Видении» (A Vision, 1925, 1927): «Many times man lives and dies/ Between his two eternities...» [19. Р. 2] («Человек - в цепи звено,/ Ибо в нем заключено/ Два бессмертья: не умрет/ Ни душа его, ни род» [пер. - Г. М. Кружкова] [9. С. 355]).

В финале «Бен-Балбена» Йейтс рисует сельский пейзаж, в центре которого - его могила. Завершается стихотворение эпитафией:

Cast a cold eye

On life, on death.

Horseman, pass by! [19.P. 4]

(Холодно встреть/ Жизнь или смерть. // Всадник, скачи! [пер. Г.М. Кружкова] [9. С. 357])

Образы холода («cold еуе» / «холодный взгляд» ${ }^{1}$ ), пустоты («bare Ben Bulben's head» / «голая верхушка Бен-Балбена») и простоты («No marble, no conventional phrase» / «Ни мрамора, ни традиционных слов»), которыми завершается стихотворение Йейтса, становятся основой для первой части стихотворения Одена «Памяти У.Б. Йейтса». Думается, образ замерзшего, заледеневшего города, появляющийся в первой строфе у Одена, не просто зимний пейзаж и не только метафора смерти и скорби по ушедшему поэту, но и дань йейтсовским представлениям о жизни и смерти, о смерти как очередном этапе вечной жизни, о чем-то, на что следует взглянуть «холодным взглядом». Поэтому вовсе не случайно настойчивое повторение фразы, венчающей первую строку, в конце первой части стихотворения: «What instruments we have agree/ The day of his death was a dark cold day» [13. Р. 142] («День этой смерти был, согласно показаниям/ приборов, мрачным и холодным днем» [пер. И. Бродского] [1. С. 42]).

Во второй строфе тон стихотворения начинает меняться, здесь заявляет о себе основная тема стихотворения - тема назначения поэзии - и уже - тема посмертного отделения творца от его творения: «The death of the poet was kept from his poems» [13. Ibid] («Смерть поэта не коснулась его стихотворений»). Далее утверждается трансформация поэта через его творчество в его почитателей: «Тhе current of his feeling failed; he became his admirers» [13. Р. 143] («Чувств его поток иссяк; он стал своими почитателями»). В этих строках - расхожая мысль о вечной жизни творца в его произведениях и читателях, отвлеченная от конкретной фигуры Йейтса. Лирический герой Одена продолжает свои рассуждения и замечает, что «слова покойника/ Меняются в нутре живущих» («The words of a dead man/ Are modified in the guts of the living» [13. Ibid]), но тут же замечает, что метаморфозы происходят с немногими, и поэзия в сущности ничего не меняет («poetry makes nothing happen» [13. Ibid]) и лишь выживает в этом мире («it survives» [13. Ibid]).

Любопытны формальные особенности стихотворения. Последовательно, от первой части к третьей, Оден от свободного стиха переходит к белому стиху (гекзаметру) и затем - к четырехстопному хорею, основному размеру стихотворения Йейтса «В тени Бен-Балбена». Свободный стих поддерживает образы холода, смерти, опустошенности и суетности мира, лишившегося великого поэта, и подчеркивает распад тех традиционных поэтических форм, на которые опирается поэзия Йейтса. Гекзаметр классический размер - маркирует переход от описания внешнего мира к рассуждениям о назначении поэзии и места Йейтса в литературной традиции. Четырехстопный хорей в заключительной части стихотворения акцентирует смещение фокуса на фигуру Йейтса и наделяет финальные строки настойчивым ритмом, похожим на барабанную дробь. Здесь, в противовес первым двум частям, где утверждается бессилие поэзии, лирический герой провозглашает живительную силу поэтического слова:

With the farming of a verse

Make a vineyard of the curse,

Sing of human unsuccess

In a rapture of distress;

\footnotetext{
${ }^{1}$ Здесь и далее подстрочный перевод выполнен автором данной работы, если не указано иное.
} 
In the deserts of the heart

Let the healing fountain start,

In the prison of his days

Teach the free man how to praise. [13. Ibid]

(В сельских радостях стиха/ да нальётся гроздь суха/ горьких слов: давясь слюной,/ пой людской удел дрянной,/ чтоб в пустынях душ возник/ и забил живой родник;/ чтобы стал темницу дней/ славить всяк живущий в ней [пер. - И. Бродского] [1. Р. 43]).

Это стихотворение Одена, по признанию Бродского, глубоко его впечатлило. В эссе 1983 г. «Поклониться тени» [3. С. 256] он отмечает, что был особенно поражен строчкой (которую, кстати сказать, Оден удалил в поздней редакции стихотворения) «Time...worships language and forgives/ Everyone by whom it lives;/ Pardons cowardice, conceit,/ Lays its honours at their feet» [18. P. 20] («Время... чтит язык и всех, кем он/ сущ, продлен, запечатлен,/ их грехи прощая им/ как преемникам своим» [пер. И. Бродского] [1. С. 44]). Поэт говорит о влиянии этих строк на все его последующее творчество так: «Оден действительно сказал, что время (вообще, а не конкретное время) боготворит язык, и ход мыслей, которому это утверждение дало толчок, продолжается во мне по сей день. Ибо “обожествление" это отношение меньшего к большему. Если время боготворит язык, это означает, что язык больше, или старше, чем время, которое, в свою очередь, старше и больше пространства» [3. С. 261].

Неудивительно, что именно на основе стихотворения Одена в 1965 г. Бродский пишет элегию «На смерть Т.С. Элиота». (К тому же, по иронии судьбы, Элиот, относившийся к творчеству Йейтса неоднозначно, умер, как и ирландский поэт, в январе.) Бродский заимствует у Одена многое: трехчастную структуру, общие контуры ритмической организации стихотворения, образный ряд. Оба стихотворения начинаются с описания заснеженного, застывшего города. Однако если у Одена природа «скорбит», как бы умирая вместе с поэтом, то у Бродского ничего подобного нет, для него зимний пейзаж - символ окончания творческого пути: «И дверь он запер на цепочку лет» [5. Т. 2. С. 115]. («Он» - это Элиот).

Январь совсем не по-оденовски сравнивается морем - здесь возникает важная для Бродского метафора поэта и поэзии как моря, стихии, трансцендентного, противопоставленного «суше» - миру обыденному, не поэтическому («И январем его залив вдается/ в ту сушу дней, где остаемся мы»; «Но, словно море в шумный час прилива,/ за волнолом плеснувши, справедливо/ назад вбирает волны, торопливо/ от своего ушел он торжества» [5. Т. 2. С. 115]).

Любопытны в контексте стихотворения Одена следующие строки Бродского: «Уже не Бог, а только Время, Время/ зовет его» [5. Т. 2. С. 115]. Думается, здесь речь идет о том, что поэт-человек подвластен божественной воле («Католик, он дожил до Рождества» [5. Т. 2. С. 115]), а поэт-творец суду Времени, что декларирует лирический герой Одена.

Вторая часть элегии Бродского, где появляются образы двух отчизн Элиота, Англии и Америки, вроде бы отсылает к строкам Одена, заявляющим, что «безумная...Ирландия» «свела» Йейтса «в поэзию». Если у Одена Ирландия - олицетворение национальных катаклизмов, которые получили особую интерпретацию в поэзии Йейтса, то у Бродского образы Англии и Америки играют совсем иную роль. Исследователи творчества Бродского видят во второй части совмещение библейских мотивов рождества Христова («маги» - волхвы) и распятия (образ Англии и Америки, находящихся «по сторонам его могилы», символизируют «распятие с предстоящими») [11. С. 48]. Две родины, аллегория прежней жизни, провожают поэта «на краю земли», за которым его ждет жизнь вечная.

В отличие от Одена, у Бродского отсутствует мотив бессилия поэзии, и потому «бойкий» хорей финала стихотворения не кажется чем-то неожиданным, инородным первым двум частям. Здесь - торжество поэзии, вечной жизни «в мире тел», символом которой становится лавровый венок, который должен быть снят с головы поэта и водружен у его ног. Очевидна в данном случае отсылка к Нобелевской премии, которую Элиот получил в 1948 г. (слово «лауреат» означает «увенчанный лавром»).

Финал оденовского стихотворения пронизан предчувствием надвигающейся катастрофы («In the nightmare of the dark/ All the dogs of Europe bark,/ And the living nations wait,/ Each sequestered in its hate...» [13. Р. 144] / «Ночи в скверные часы/ всей Европы лают псы;/ стран, свернувшихся в клубок/ ненависти, сон глубок» [пер. - И. Бродского] [1. С. 44]), и голос мертвого поэта воспринимается как голос свободы, способный заставить народ «ликовать» («rejoice») и «исцелить» свои раны («healing fountain» / «исцеляющий родник»). Гармонизирующая сила поэзии в стихотворении Бродского истолкована совершенно иначе. В его элегии речь идет о гармоничном сосуществовании природы и человека, стихии и рукотворного порядка. Отсюда строки: «Шум шагов и лиры звук/ будет помнить лес 
вокруг»; «Будет помнить лес и дол»; «Будет помнить каждый злак» [5. Т. 2. С. 116] и т.д. В пользу подобной трактовки заключительной части элегии говорит и упоминание Эола, ведь эолова арфа была расхожим символом творчества у поэтов-романтиков. В качестве примера можно привести строки из стихотворения «Эолова арфа» (The Eolian Harp, 1796) С. Кольриджа:

And what if all of animated nature

Be but organic Harps diversely framed,

That tremble into thought, as o'er them sweeps

Plastic and vast, one intellectual breeze,

At once the Soul of each, and God of all? [14. P. 237]

(А что, когда вся сущая природа -/ Собрание живых и мертвых арф,/ Что мыслями трепещут, если их/ Коснется ветер, беспредельный, мудрый, -/ И каждого Душа и Бог Всего? [пер. В. Рогова] [8. C. 82])

Элегия Бродского не завершает собой цепочку парафразов «Йейтс - Оден - Бродский». Есть еще как минимум одно звено - стихотворение Шеймаса Хини «Размером Одена» (Audenesque, 1996), написанное на смерть Бродского. Элегия Хини подчеркнуто интертекстуальна: поэт практически прямо говорит о метрической цитации стихотворения Одена у себя и Бродского («Джозеф, помнишь этот ритм?// Оден, твой любимый бритт,/ Брел под гул таких же стоп,/ Провожая Йейтса в гроб» [пер. Г.М. Кружкова] [12. С. 165] / «Joseph, yes, you know the beat/ Wystan Auden's metric feet/ Marched to it, unstressed and stressed,/ Laying William Yeats to rest» [16. P. 77]). Иными словами, это стихотворение дань памяти не только Бродскому, но и способ осмыслить литературную традицию, частью которой он стал. Именно поэтому во второй строфе Хини обращает внимание на удивительное совпадение Бродский ушел из жизни в годовщину смерти Йейтса, 28 января. Параллель, проводимая Хини и самой жизнью, как бы возвышает творчество Бродского до уровня поэзии Йейтса и косвенно ставит Хини в один ряд с великими поэтами XX в. («Its measured ways I tread again» [16. Ibid] / «Я шагаю вам вослед» [пер. Г.М. Кружкова] [12. С. 165]).

В стихотворении Хини заявляет о себе мотив повторяемости: чередование метрических единиц, составляющее ритмический рисунок стихотворения (четвертая строфа), метафорически выражает неизбежный итог жизни - смерть плоти (пятая строфа). И здесь возникают, казалось бы, те же, что у Одена и Бродского, образы стужи, снега и льда, символизирующие смерть и скорбь. И все же у Одена и Бродского эти образы сконцентрированы во внешнем мире, вне поэта. Иначе у Хини - лед смерти сделал из сердца поэта «замерзшую дыру» («Iсе.../ Makes your heart a frozen well» [16. Р. 78]), а его грудь охватило трупное окоченение («rigor mortis in your breast» [16. P. 78]).

Вообще, элегия Хини глубоко личная. Не случайно лирический герой обращается напрямую к Бродскому: «Джозеф, помнишь этот ритм?» [пер. - Г. М. Кружкова] [12. С. 165] / «Joseph, yes, you know the beat» [16. Р. 78]; «Поэтому, Джозеф, в этот день...»/ «Therefore, Joseph, on this day» [16, ibid]; «Как ты сказал...» / «As you said» [16. Ibid] и т.д. В стихотворении лирическое «я» у Хини вспоминает Бродского в первую очередь как личность, друга, который - так уж вышло - еще и поэт. Эти воспоминания наполнены теплотой, образами жизни, и противопоставлены ликам смерти из первой половины стихотворения: «Водка с перцем.../ Для согрева, для души» [пер. Г.М. Кружкова] [12. С. 165]/ «Pepper vodka you produced/... Warmed my spirits and my heart» [16. Р. 79]; «кровь к твоим щекам» / «blood back to your cheeks» [16. Ibid]; «цвет твоих шуток» / «colour to your jokes» [16. Ibid]; «пьющий, курящий как паровоз» / «drinking, smoking like a train» [16. Ibid] и т.д. Анафорически повторяющееся слово «nevermore» («больше никогда») подчеркивает необратимость смерти поэта, невозвратность тех моментов счастья, которые лирический герой испытал вместе с другом.

Хини завершает «беседу» с другом рассуждениями на тему времени, которые перекликаются со стихотворением Одена и впечатлениями Бродского от него. По Одену, «время... чтит язык и всех, кем он сущ, продлен, запечатлен», и все же, как замечает лирической герой Хини, «почитаемый язык не может обернуть вспять/ разрушительное влияние времени» на личность поэта, то есть его смерть («Worshipped language can’t undo/ Damage time has done to you» [16. Р. 80]). По мысли Одена, смерть поэта отменяет все его прегрешения, но также, по всей видимости, время беспощадно и к личности поэта в целом. Именно с этим не согласен Хини: в своем стихотворении он совершает попытку увековечить Бродского в первую очередь как личность, как друга. Неслучайно упоминание Гильгамеша, правителя одного из шумерских городов, который, по легенде, был одержим идеей обрести бессмертие, но в итоге свыкся с тем, что оно недостижимо. Именно с мыслями о невозможности бессмертия, лишенными оттенка торжественности и тем более ликования, провожает друга в последний путь Хини. 
Последние две строки ироничны и одновременно критичны по отношению к Одену: «Делай то, что, как Оден говорил,/ Делают хорошие поэты: вкуси их хлеб» («Do again what Auden said/ Good poets do: bite, break their bread» [16. Ibid]). Думается, в интерпретации Хини строки Одена о времени означают, что хороший поэт - мертвый поэт, с чем, конечно, Хини не согласен. Ни один поэт, впрочем, не избежит смерти и каждый «вкусит» ее «хлеб».

Любопытно, что ритмы элегии Одена и ее «последователей» были переняты современным американским поэтом Джоном Мэттиасом (John Matthias, 1943) в его стихотворении «Элегия на смерть Шеймаса Хини» (Elegy for Seamus Heaney, 2013) [15. Р. 201].

В заключение скажем несколько слов о стихотворении, которое Бродский посвятил Хини («Я проснулся от криков чаек в Дублине...», 1990). Это стихотворение написано поэтом прежде всего для поэта и к нему обращено; это стихотворение - о поэзии, поэтическом слове и о том, что оно таит; это стихотворение - о муках творчества, о невыразимом, вечно ускользающем, о «конце грамматики». Образы сна, «окаменелости», беспомощности, слепоты, «мертвого парка», притупленности чувств все они отсылают к состоянию поэта, отчаявшегося выразить в слове первозданное звучание мира.

Между тем это еще и исповедь поэта в изгнании, для которого поэтическое невыразимое приобретает новый, вполне конкретный смысл, связанный с языковым барьером («нечленораздельный вопль» [5. Т. 4. С. 97]).

Лирическому герою Бродского кажется, что «он - дома, а точнее - возле» [5. Т. 4. С. 97]. Очевидно, речь идет о неких ассоциациях, которые возникают у только что пробудившегося героя, находящегося где-то между сном и явью: «крики чаек» напоминают ему о Ленинграде, который, как и Дублин, портовый город; «мертвый парк», в котором «маячат изваяния», тоже образ вполне петербургский (ср. с Рильке: «Летний сад в задумчивом томленьи.../И летят копыта рысака/ мимо легких этих изваяний,/ мимо неуснувших этих зданий,/ мимо их дремотных очертаний...[пер. Т. Сильман] [7. С. 28]). Именно вспоминание родины заставляет героя «вздрогнуть», на мгновение выйти из состояния «окаменелости»: по словам Бродского, творчество изгнанника неизбежно ретроспективно, обращено к прежнему поэтическому опыту.

Параллель с Дублином здесь возникает не только и не столько в связи с Хини, но, думается, главным образом вослед Джойсу, покинувшему Ирландию и все же неизменно помещавшему своих героев в Дублин. Подтверждение этого предположения находится в эссе Бродского «Состояние, которое называется изгнание»: «Если заговорить с ним на эту тему, писатель-эмигрант, весьма вероятно, вспомнит Рим Овидия, Флоренцию Данте и - после небольшой паузы - Дублин Джойса» [4. С. 31 ].

Там же можно прочитать: «"И ты далеко в человечности”, как сказал Китс. Затеряться в человечестве, в толпе - толпе ли? - среди миллиардов; стать пресловутой иголкой в этом стоге сена - но иголкой, которую кто-то ищет, - вот к чему сводится изгнание. "Оставь свое тщеславие, - говорит оно, - ты всего лишь песчинка в пустыне. Соизмеряй себя не со своими собратьями по перу, но с человеческой бесконечностью: она почти такая же дурная, как и нечеловеческая. Ты должен говорить исходя из нее, а не из своих зависти и честолюбия". Ясно, что этот призыв остается неуслышанным» [4. С. 29]. Возможно, это та самая «чистая бесчеловечная нота», о которой поэт говорит в стихотворении. Если так, то бесчеловечна она потому, что не соотносится с «человеческой бесконечностью», потому что это «нота» поэтическая, надмирная, метафизическая. Отсюда же «нечленораздельность» слова - оно не только и не всегда иностранное - оно еще и поэтическое.

Ощущение «беспомощности», «ярости» творца в изгнании объясняются, по Бродскому, его «перемещенностью и неуместностью», «трагикомичностью» его жизненной ситуации, когда «демократия, в которую он прибыл, дает ему физическую безопасность, но делает его социально незначительным» [4. С. 29].

Выводы. Следует заметить, что самоощущение Бродского как поэта-изгнанника не помешало ему вписать свое имя (и оказаться вписанным) как минимум в общеевропейскую элегическую традицию. Бродский - автор нескольких десятков элегий и стихотворений-посвящений. Со свойственной поэту самоиронией поэт отзывался о своей любви к этому жанру: «Я был тогда молод и потому особенно увлекался жанром элегии, не имея поблизости умирающего, кому я мог бы ее посвятить» [4. С. 29]. В одном из поздних эссе («Трагический элегик», 1991) Бродский дает иное объяснение этому интересу: «Причиной тому отчасти свойственное любому человеческому существу ощущение, что бытие обретает статус реальности главным образом постфактум, отчасти - тот факт, что самое движение пера по бумаге есть, говоря хронологически, процесс ретроспективный. В этом смысле все сущее на бумаге, включая утопию, есть элегия» [6. С. 148]. 


\section{СПИСОК ИСТОЧНИКОВ И ЛИТЕРАТУРЫ}

1. Бродский И. Изгнание из рая. Избранные переводы / Под ред. Я. Клоца. СПб.: Азбука, 2010. 304 с.

2. Бродский И. Как читать книгу // Сочинения Иосифа Бродского / Под ред. Я.А. Гордина. СПб.: Пушкинский фонд, 2001. Т. 6. С. 80-85.

3. Бродский И. Поклониться тени // Сочинения Иосифа Бродского / Под ред. Я.А. Гордина. СПб.: Пушкинский фонд, 2001. Т. 5. С. 256-274.

4. Бродский И. Состояние, которые мы называем изгнанием // Сочинения Иосифа Бродского / Под ред. Я.А. Гордина. СПб.: Пушкинский фонд, 2001. Т. 6. С. 27-36.

5. Бродский И. Сочинения Иосифа Бродского. Т. 1-7 / Под ред. Я.А. Гордина. СПб.: Пушкинский фонд, 2001.

6. Бродский И. Трагический элегик // Сочинения Иосифа Бродского / Под ред. Я.А. Гордина. СПб.: Пушкинский фонд, 2001. Т. 7. С. 147-155.

7. Западноевропейская лирика / Сост. Н.Я. Рыкова. Л.: Лениздат, 1974. 568 с.

8. Кольридж С. Стихи. М.: Наука, 1974. 280 с.

9. Кружков Г.М. Луна и дискобол. О поэзии и поэтическом переводе. М.: РГГУ, 2012. 511с.

10. Куллэ В. Иосиф Бродский: новая Одиссея // Сочинения Иосифа Бродского / Под ред. Я.А. Гордина. СПб.: Пушкинский фонд, 2001. Т. 1. С. 283-297.

11. Соколов К.С. И. Бродский и У.Х. Оден: к проблеме усвоения английской поэтической традиции: дис. ... канд. филол. наук. Владимир, 2003. 213 с.

12. Хини Ш. Школа пения. Стихотворения 1966-2002 / Пер. Г. М. Кружкова. М.: Центр книги Рудомино, 2003. $223 \mathrm{c}$.

13. Auden W.H. Collected Shorter Poems. L.: Faber\&Faber, 1966. 351 p.

14. Coleridge S. The Poetical Works of Samuel Taylor Coleridge. N.Y.: D. Appleton, 1857. 388 p.

15. Connolly S. Grief and Meter: Elegies for Poets after Auden. Charlottesville: University of Virginia Press, 2016.272 p.

16. Heaney S. Electric Light: Poems. N.Y.: Farrar, Straus and Giroux, 2014. 144 p.

17. Schwerter S. Northern Irish Poetry and the Russian Turn. L.: Macmillan, 2013. 251 p.

18. The Oxford Handbook of Contemporary British and Irish Poetry / Ed. by P. Robinson. Oxford: OUP, 2013.784 p.

19. Yeats W. B. Last Poems and Two Plays. Dublin: The Cuala Press, 1939. 58 p.

Поступила в редакцию 03.07.2019

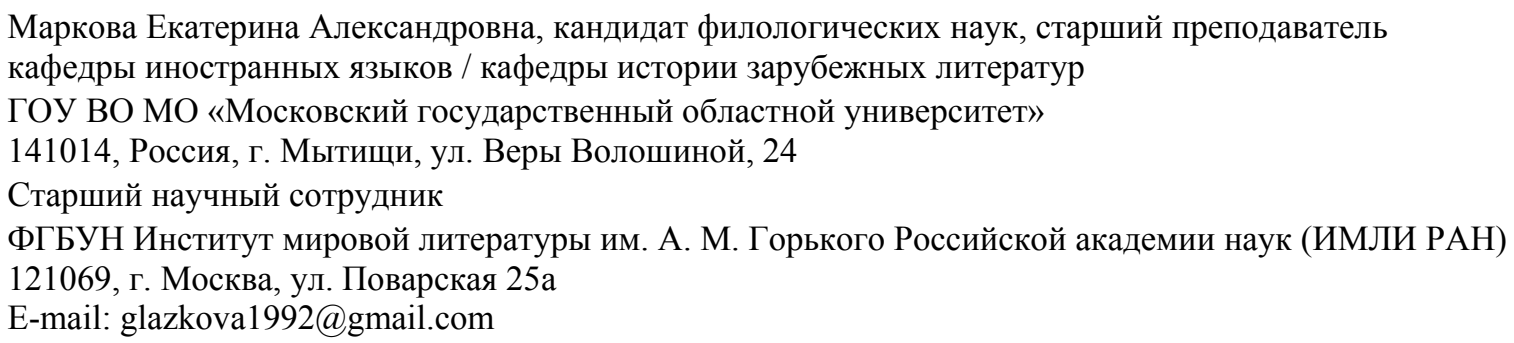

\section{E.A. Markova}

THE TRADITION OF ENGLISH-LANGUAGE ELEGY AND J. BRODSKY's POETRY

DOI: $10.35634 / 2412-9534-2019-29-6-1030-1036$

In the present article J. Brodsky's poetry is analyzed in the context of a particular elegiac tradition associated with some key figures of English-language poetry of the mid-to-late 20th century. These are W.B. Yeats, T.S. Eliot, W.H. Auden and S. Heaney. The aim of the article is to examine the continuity of the 20th century English poetry by the example of a sequence of dedication poems (elegies), in which each subsequent poem alludes to the previous one(s). The comparative method allows us not only to show the features of modern English-language poetry (for instance, the link between elegiac mood and reflection on the purpose of poetry), but also to analyze the influence of poets' interpersonal contacts on their works. Special emphasis is put on J. Brodsky's poetry as it may seem extraneous to the English-language tradition in question. The analysis of Brodsky's personal and creative biography, his particular dedication poems and essays allows us to find the links between the Russian poet and the literary tradition of Great Britain, Ireland and the USA.

Keywords: interrelations between literatures; elegy; dedication poems; J. Brodsky; S. Heaney. 


\section{REFERENCES}

1. Brodskij I. Izgnanie iz raja. Izbrannye perevody [The Expulsion from Paradise. Selected translations] / Pod red. Ja. Kloca [ed. J. Kloc]. SPb.: Azbuka, 2010. 304 s. [Spb.: Azbuka, 2010. 304 p.]. (In Russian).

2. Brodskij I. Kak chitat' knigu [How to read a book ] // Sochinenija Iosifa Brodskogo [Joseph Brodsky's writings] / Pod red. Ja.A. Gordina [ed. J. A. Gordin]. SPb.: Pushkinskij fond, 2001. T. 6. S. 80-85. [Spb.: Pushkin Fund, 2001. Vol. 6. Pp. 80-85]. (In Russian).

3. Brodskij I. Poklonit'sja teni [To Please a Shadow] // Sochinenija Iosifa Brodskogo [Joseph Brodsky's writings] / Pod red. Ja.A. Gordina [ed. J. A. Gordin]. SPb.: Pushkinskij fond, 2001. T. 5. S. 256-274. [Spb.: Pushkin Fund, 2001. Vol. 5. Pp. 256-274]. (In Russian).

4. Brodskij I. Sostojanie, kotorye my nazyvaem izgnaniem [Condition which We Call Exile] // Sochinenija Iosifa Brodskogo [Joseph Brodsky's writings] / Pod red. Ja.A. Gordina [ed. J. A. Gordin]. SPb.: Pushkinskij fond, 2001. T. 6. S. 27-36. [Spb.: Pushkin Fund, 2001. Vol. 6. Pp. 27-36]. (In Russian).

5. Brodskij I. Sochinenija Iosifa Brodskogo. T. 1-7. [Joseph Brodsky's writings. Vol. 1-7] / Pod red. Ja.A. Gordina [ed. J. A. Gordin]. SPb.: Pushkinskij fond, 2001. [Spb.: Pushkin Fund, 2001]. (In Russian).

6. Brodskij I. Tragicheskij jelegik [Tragic Elegiac Poet] // Sochinenija Iosifa Brodskogo [Joseph Brodsky's writings] / Pod red. Ja.A. Gordina [ed. J. A. Gordin]. SPb.: Pushkinskij fond, 2001. T. 7. S. 147-155. [Spb.: Pushkin Fund, 2001. Vol. 7. Pp. 147-155]. (In Russian).

7. Zapadnoevropejskaja lirika [Western European Lyric Poetry] / Sost. N.Ja. Rykova [ed. N. J. Rykova]. L.: Lenizdat, 1974. 568 s. [Leningrad: Lenizdat, 1974. 568 p.]. (In Russian).

8. Kol'ridzh S. [Coleridge S.] Stihi [Poems]. M.: Nauka, 1974. 280 s. [M.: Nauka, 1974. 280 p.]. (In Russian).

9. Kruzhkov G. M. Luna i diskobol [The Moon and the Discobolos]. O pojezii i pojeticheskom perevode [On Poetry and Poetic Translation]. M.: RGGU, 2012. 511s. [M.: RGGU, 2012. 511 p.]. (In Russian).

10. Kullje $V$. Iosif Brodskij: novaja Odisseja [Joseph Brodsky: A New Odyssey] // Sochinenija Iosifa Brodskogo [Joseph Brodsky's writings] / Pod red. Ja.A. Gordina [ed. J. A. Gordin]. - SPb.: Pushkinskij fond, 2001. T. 1. S. 283297. [Spb.: Pushkin Fund, 2001. Vol. 1. Pp. 283-297]. (In Russian)

11. Sokolov K. S. I. Brodskij i U.H. Oden: k probleme usvoenija anglijskoj pojeticheskoj tradicii. Diss. ... kand. filol. nauk [J. Brodsky and W.H. Auden: On the Issue of the Adoption of English Poetic Tradition]. Vladimir, $2003.213 \mathrm{~s}$ [Vladimir: 2003. 213 p.]. (In Russian).

12. Hini Sh. [Heaney S.] Shkola penija. Stihotvorenija 1966-2002 [Singing School. Poems 1966-2002] / Per. G. M. Kruzhkova [Trans. G.M. Kruzhkov]. M.: Centr knigi Rudomino, 2003. 223 s. [M.: Centr knigi Rudomino, 2003. 223 p.]. (In Russian).

13. Auden W. H. Collected Shorter Poems. L.: Faber\&Faber, 1966. 351 p. (In English).

14. Coleridge $S$. The Poetical Works of Samuel Taylor Coleridge. N.Y.: D. Appleton, 1857. 388 p. (In English).

15. Connolly S. Grief and Meter: Elegies for Poets after Auden. Charlottesville: University of Virginia Press, 2016. 272 p. (In English).

16. Heaney S. Electric Light: Poems. N.Y.: Farrar, Straus and Giroux, 2014. 144 p. (In English).

17. Schwerter S. Northern Irish Poetry and the Russian Turn. L.: Macmillan, 2013. 251 p. (In English).

18. The Oxford Handbook of Contemporary British and Irish Poetry / Ed. by P. Robinson. Oxford: OUP, 2013.784 p. (In English).

19. Yeats W. B. Last Poems and Two Plays. Dublin: The Cuala Press, 1939. 58 p. (In English).

Markova E.A., Candidate of Philology, Senior Lecturer at Department of Foreign Languages /

Department of Foreign Literatures

Moscow Region State University

Very Voloshinoy st., 24, Mytischi, Russia, 141014

Senior researcher

A.M. Gorky Institute of World Literature of the Russian Academy of Sciences

Povarskaya st., 25a, Moscow, Russia, 121069

E-mail: glazkova1992@gmail.com 